REVIEW

\title{
Assessment of hypoxia in children with cystic fibrosis
}

\author{
D S Urquhart, H Montgomery, A Jaffé
}

Arch Dis Child 2005;90:1138-1143. doi: 10.1136/adc.2005.071795

\begin{abstract}
Hypoxia during sleep and exercise may occur in an important number of patients with cystic fibrosis (CF). Despite its recognition, no clear definition for hypoxia in CF exists, and nor do guidelines for commencing oxygen therapy. CF patients with hypoxia may have increased pulmonary artery pressure, reduced exercise ability, and skeletal muscle strength, and most importantly of all worse sleep quality, and a worse quality of life. Laboratory and rodent evidence exists to suggest that hypoxia may contribute to the decline in lung function in CF by upregulating lung inflammation, and encouraging growth of Pseudomonas aeruginosa, the most important pathogen associated with CF lung disease. The effects of hypoxia in childhood CF need to be fully studied, and a potential expanded role for oxygen as therapy in CF may be worthy of exploration.
\end{abstract}

See end of article for authors' affiliations

Correspondence to: Dr D S Urquhart, Cystic Fibrosis Research Fellow, Cystic Fibrosis Office, Level 8, Old Nurses Home, Great Ormond Street Hospital, London WCIN 3JH, UK; UrquhD@gosh. nhs.uk

Accepted 18 July 2005

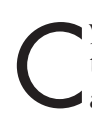
ystic fibrosis (CF) is the most common life threatening inherited disease in the UK, affecting over 7500 children and young adults. Average life expectancy is currently 31 years (www.cftrust.org.uk). Abnormal airway surface liquid results in recurrent lower respiratory tract infections and airway remodelling, leading to increased airway resistance, gas trapping, ventilation-perfusion mismatching, and increased work of breathing.

Episodic hypoxaemia may occur at times of physiological stress in CF, such as sleep, ${ }^{12}$ exercise, ${ }^{3}$ air travel, ${ }^{4}$ and during infective exacerbations of CF. Hypoxia during sleep and exercise is reported to occur in stable adult CF patients who are not hypoxic during the day, when compared to healthy controls. ${ }^{1}$ Furthermore, studies have shown significantly lower mean resting ${ }^{5}$ and overnight ${ }^{2} \mathrm{SaO}_{2}$ in stable CF children when compared to controls. During sleep, tidal volume falls due to reduced respiratory drive, precipitating hypoxia, ${ }^{1}$ although upper airway obstructive pathology such as nasal polyps may also contribute, while exercise induced hypoxia may be related to airflow limitation, ${ }^{1}$ or accentuation of V/Q mismatch.

This review aims to summarise the potential impact of hypoxia in childhood CF. At present, only $1-2 \%$ of childhood CF patients receive long term oxygen therapy at night, ${ }^{6}$ and no guidelines exist on when to start oxygen, nor how to define hypoxaemia in childhood CF. There is a paucity of evidence to drive clinical practice in this area, and extensive literature searching identifies only one randomised, controlled trial (RCT) of long term oxygen therapy in $\mathrm{CF}^{7}$

\section{DEFINING HYPOXIA IN CF}

Children with CF may suffer reduced arterial oxygen saturation $\left(\mathrm{SaO}_{2}\right)$ during sleep and while exercising. The failure of a clear definition of "significant hypoxaemia" hampers the description of its prevalence and severity. In adults, measurement of arterial $\mathrm{PaO}_{2}$ is considered critical, but this is not always possible or practical in children. In paediatric practice, $\mathrm{SaO}_{2}$ measured by pulse oximetry remains the main assessment tool. Arterial sampling from a crying (hypoxic) child is unreliable, ${ }^{6}$ while capillary $\mathrm{PaO}_{2}$ may not reflect arterial $\mathrm{PaO}_{2}{ }^{8}$ Although pulse oximetry is a freely available, non-invasive method of assessing oxygenation, correlation between $\mathrm{SaO}_{2}$ and arterial $\mathrm{PaO}_{2}$ may be poor, ${ }^{9}$ and limits of accuracy for $\mathrm{SaO}_{2}$ are $\pm 2 \%{ }^{9}$

\section{Sleep hypoxaemia in CF}

A study of stable CF children has shown significantly lower mean overnight $\mathrm{SaO}_{2}$ when compared to controls, ${ }^{2}$ but an e-mail survey of all UK paediatric CF centres found that less than a quarter have a clear definition of nocturnal hypoxia. ${ }^{10}$ One such definition of sleep hypoxia is nocturnal $\mathrm{SaO}_{2}<93 \%$ for $>25 \%$ of the study. ${ }^{10}$ However, various methods of quantifying nocturnal $\mathrm{SaO}_{2}$ in CF studies of adults and children are reported, including percentage of time spent with $\mathrm{SaO}_{2}$ below $90 \%,{ }^{11}$ minimum $\mathrm{SaO}_{2}{ }^{12}$ mean sleep $\mathrm{SaO}_{2},{ }^{13}{ }^{14}$ and lowest hourly mean $\mathrm{SaO}_{2} \cdot{ }^{15}$ Normative data for nocturnal $\mathrm{SaO}_{2}$ in children, ${ }^{16}$ quote mean (Sat 50) and minimum (Sat min) $\mathrm{SaO}_{2}$ values, as well as $\mathrm{SaO}_{2}$ values below which $10 \%$ (Sat 10 ) and $5 \%$ (Sat 5) of the study were spent. Some studies cited above have chosen a cut-off for hypoxaemia (for example, mean $\mathrm{SaO}_{2}$ $<95 \%){ }^{13}$ creating dichotomous results; whereas others record mean $\mathrm{SaO}_{2}$ on a continuum using linear regression and correlation to explore relations with other variables. ${ }^{14}$

Currently it is unclear at what level oxygen desaturation becomes important during sleep, but clearly this may be a chronic, frequently repeated hypoxic insult and as such may impact on factors such as pulmonary circulation ${ }^{17}$ and sleep quality, ${ }^{18}$ as well as theoretical effects on lung inflammation, ${ }^{19}$ and potentially Pseudomonas aeruginosa (PA) growth. ${ }^{20}$

\section{Exercise hypoxaemia in CF}

Exercise induced arterial hypoxaemia (EIAH) in children with CF has been defined as a fall in $\mathrm{SaO}_{2}$ during exercise of $\geqslant 4 \%$ from baseline, ${ }^{3}$ and this definition has also been used in healthy children. ${ }^{21}$ Our own (unpublished) data from 2004 showed that 8\% have EIAH using these criteria when assessed using an incremental 
submaximal exercise test ( 3 minute step test). The UK CF Trust "Clinical guidelines for cystic fibrosis care" 22 recommend annual exercise testing, but no guidelines exist for managing exercise induced arterial hypoxaemia (EIAH). There seems little point in subjecting CF patients to a barrage of tests if we are to ignore the results, yet it is unclear as to how exercise testing should be used to inform treatment. In adolescent and adult CF patients, hypoxia is reported to occur more frequently during sleep than on exercise, ${ }^{13}$ suggesting a sleep study may be indicated for those with EIAH.

\section{Hypoxaemia and chest exacerbations of CF}

Children may face challenges to their pulmonary reserve at times of infective exacerbations. At such times, ventilationperfusion mismatching may be exaggerated and resultant hypoxaemia may ensue. Admission to hospital for intravenous antibiotics is an opportunity for monitoring $\mathrm{SaO}_{2}$. Appropriate antibiotic therapy, and aggressive physiotherapy may result in improvement in lung function over the course of an admission such that there is no longer a need for oxygen at the end of an antibiotic course. In adult CF patients, it is reported that minimum $\mathrm{SaO}_{2}$ are lower and time spent with $\mathrm{SaO}_{2}<90 \%$ is greater in patients with chest exacerbations than those with stable $\mathrm{CF}^{23}$ and treating the chest exacerbation significantly improves these indices.

\section{Hypoxaemia and fitness to fly}

Flying heightens the risk of hypoxaemia in susceptible individuals, as both barometric pressure and partial pressure of oxygen fall with altitude, such that airline passengers breathe air with an inspired oxygen concentration $\left(\mathrm{FiO}_{2}\right)$ of $15 \%$. In-flight hypoxia is defined as a fall in $\mathrm{SaO}_{2}$ to below $90 \%$ at some point during the flight. ${ }^{4}$ The main methods used to predict hypoxia in "fitness to fly" assessments have been to undertake a pre-flight hypoxic challenge, ${ }^{42}$ or to predict in-flight hypoxaemia on the basis of baseline measures such as spirometry ${ }^{4}$ or $\mathrm{PaO}_{2} \cdot{ }^{25}$ Buchdahl and colleagues suggest that \%predicted $\mathrm{FEV}_{1}$ below $50 \%$ correctly identifies $70 \%$ of those with in-flight hypoxia, and is also $96 \%$ specific, compared with $20 \%$ sensitivity for pre-flight hypoxic challenge. The British Thoracic Society guidelines suggest that children with CF should undergo pre-flight assessment which "may include hypoxic challenge testing in addition to spirometric tests", ${ }^{26}$ and the updated recommendations of Buchdahl and colleagues are that a hypoxic challenge be undertaken if $\mathrm{FEV}_{1}$ is below $50 \%$ predicted. ${ }^{27}$

\section{Does daytime $\mathrm{SaO}_{2}$ predict nocturnal and exercise desaturation in $\mathrm{CF}$ ?}

It is routine practice in CF clinics to record resting $\mathrm{SaO}_{2}$, and values $\leqslant 93 \%$ indicate a high risk of nocturnal hypoxaemia in $\mathrm{CF} .{ }^{15}$ There are no published childhood data on the predictive value of daytime oximetry in CF. However, in 70 CF adults, $40 \%$ of whom had significant nocturnal hypoxaemia, ${ }^{11}$ all subjects with resting $\mathrm{SaO}_{2}<93 \%$ had significant nocturnal desaturation, but $36 \%$ patients with resting $\mathrm{SaO}_{2}>93 \%$ also became hypoxic at night. These data are supported by another study, ${ }^{14}$ which reports that resting $\mathrm{SaO}_{2}<94 \%$ correctly predicts $100 \%$ with nocturnal hypoxaemia, but misses $19 \%$ of patients with $\mathrm{SaO}_{2}>94 \%$ who also become hypoxic at night. Therefore, although resting $\mathrm{SaO}_{2}<93 \%$ may be specific for predicting nocturnal desaturation, a sleep study may be needed to confidently detect sleep hypoxia.

The only RCT of oxygen therapy in CF determined nocturnal oxygen flows by titrating the amount required to normalise daytime $\mathrm{pO}_{2}{ }^{7}$ Since daytime oxygenation is a poor predictor of overnight hypoxia, ${ }^{11}{ }^{14}$ it may be that despite oxygen therapy, the oxygen treated group remained hypoxic at night. Further research may be required in order to more carefully define the tissue effects of hypoxia in CF, and to carry out rigorous RCTs of oxygen therapy in CF in order to determine its efficacy, and the optimum point for intervention.

\section{IS HYPOXIA IMPORTANT IN CF?}

Hypoxia in CF is potentially important for several reasons (table 1). Nocturnal and/or exercise hypoxia are chronic, frequently repeated insults which may affect the pulmonary circulation, ${ }^{17}$ exercise ability (fig 1 ), and quality of life. ${ }^{78}$, as well as exerting theoretical effects on lung inflammation, ${ }^{19}$ and the bacterial profile in the CF lung, ${ }^{20}{ }^{28}$ The effects of a hypoxia driven pro-inflammatory state on muscle wasting ${ }^{29}$ may also be important in disease progression in $\mathrm{CF}$.

\section{HYPOXIA AND THE PULMONARY CIRCULATION}

The effects of chronic hypoxia on the pulmonary circulation are well documented, and the first case report of cor pulmonale in CF dates from 1946. ${ }^{33}$ The pulmonary circulation responds to alveolar hypoxia by increasing systolic pulmonary artery pressure (sPAP) and pulmonary vascular resistance (PVR). Graded decreases in alveolar $\mathrm{pO}_{2}\left(\mathrm{P}_{\mathrm{A}} \mathrm{O}_{2}\right)$ produce similar increases in PVR. ${ }^{34}$ Chronic hypoxia results in pulmonary arterial remodelling, with increased intimal thickness, which concurs with paediatric CF postmortem studies. ${ }^{35}$

Both sleep and exercise induced hypoxia are likely to be chronic, frequently occurring insults. A significant negative correlation between sPAP and mean $\mathrm{SaO}_{2}$ during sleep $(r=-0.56, \quad \mathrm{p}<0.008), \quad$ and exercise $\quad(r=-0.75$, $\mathrm{p}<0.0001)$ is reported in CF adults. ${ }^{17}$ Therefore if pulmonary hypertension directly relates to degree of sleep and/or exercise hypoxaemia, then provision of oxygen at night and/ or during exercise might be expected to result in beneficial effects on the right heart and pulmonary circulation.

\section{HYPOXIA AND EXERCISE ABILITY}

Ability to exercise is important for preservation of lung function in CF, as well as having proven beneficial effects on quality of life. ${ }^{36}$ Hypoxia may drive lung inflammation ${ }^{19}$ and encourage Pseudomonas aeruginosa (PA) growth in the CF lung, ${ }^{28}$ each worsening lung damage, and accelerating skeletal muscle dysfunction. ${ }^{29}$ Deteriorating lung function, combined with reduced muscle mass, ${ }^{29}$ limits exercise capacity and may instigate a vicious circle (fig 1) whereby decreased exercise ability reduces sputum clearance, encouraging bacterial growth within the CF lung. Inflammation may be perpetuated, causing further reductions in lung function and exercise ability. The effects of hypoxia on the heart and pulmonary circulation may further limit exercise. ${ }^{37}$

Oxygen therapy may down-regulate inflammation, halting the catabolic effects of a pro-inflammatory state. ${ }^{29}$ The combination of reduced lung inflammation and improved skeletal muscle strength, as well as potential beneficial effects on the pulmonary circulation, may improve exercise ability.

Provision of oxygen during exercise in both $\mathrm{CF}^{38}{ }^{39}$ and adult chronic obstructive pulmonary disease $(\mathrm{COPD})^{40}$ is known to reduce work of breathing and breathlessness, as well as increasing exercise endurance. However, maximal oxygen uptake $\left(\mathrm{VO}_{2 \max }\right)$ in CF changes little, suggesting that CF patients may have impaired utilisation of oxygen at skeletal muscle level, ${ }^{41}$ which may reflect the catabolic effects of hypoxia on skeletal muscle. ${ }^{29}$ A beneficial role for oxygen therapy alongside a pulmonary exercise rehabilitation programme has been reported in adult chronic obstructive pulmonary disease (COPD) patients, ${ }^{42}$ and may be an area that warrants further investigation in patients with CF. 
Table 1 Potential adverse effects of hypoxia in CF

\begin{tabular}{|c|c|}
\hline & Adverse effect \\
\hline Pulmonary circulation & Increased pulmonary artery pressures related to levels of sleep and exercise hypoxaemia ${ }^{17}$ \\
\hline Lung inflammation & $\begin{array}{l}\text { Up-regulated cytokine expression }{ }^{19} \text { with increased neutrophil chemoattraction, neutrophilic inflammation, and resultant } \\
\text { parenchymal lung damage }\end{array}$ \\
\hline Bacterial profile in the CF lung & $\begin{array}{l}\text { Enhanced } P \text { aeruginosa growth in biofilms }{ }^{20} \text { with increased antibiotic resistance }{ }^{28} \\
\text { Possible increased } S \text { aureus virulence } e^{30}\end{array}$ \\
\hline Exercise ability & $\begin{array}{l}\text { Limited exercise ability due to effects on pulmonary vasculature and also lung inflammation and bacterial colonisation. } \\
\text { Reduced exercise ability sets up "vicious circle" (fig 1) }\end{array}$ \\
\hline Muscle strength & Reduced skeletal muscle mass ${ }^{29}$ \\
\hline Quality of life & $\begin{array}{l}\text { Potential adverse effects on quality of life, including maintenance of school or work attendance } \\
\text { Poor sleep quality }\end{array}$ \\
\hline Endothelium & Endothelial dysfunction ${ }^{31}$ \\
\hline (CFTR trafficking) & Reduced CFTR protein trafficking shown in vitro under hypoxic conditions in a non-CF cell line ${ }^{32}$ \\
\hline & Effects not documented in a CF cell line \\
\hline
\end{tabular}

\section{HYPOXIA AND QUALITY OF LIFE IN CF}

In the only randomised, controlled trial (RCT) of LTOT in $\mathrm{CF}^{7}{ }^{7}$ a cohort of 28 adults and children with severe CF lung disease received either oxygen or air at night. The double blind, placebo controlled trial lasted three years. Although no differences in mortality or hospitalisation rates were found between the two groups, school and/or work attendance continued in a significantly higher proportion of the oxygen group $(80 \%$ versus $20 \%, \mathrm{p}<0.01)$. This suggests that patients felt better in oxygen, although psychometric testing revealed no significant differences between groups. Sleep quality (Pittsburgh Sleep Quality Index, $r=-0.4, \mathrm{p}<0.05$ ) and sleep duration $(r=-0.4, \mathrm{p}<0.05)$ in CF have been reported to negatively correlate with minimum $\mathrm{SaO}_{2}$ during sleep. ${ }^{18}$ It has also been reported that neurocognitive performance is impaired during chest exacerbations of $\mathrm{CF}$, at a time when this group of subjects were hypoxic. ${ }^{23}$ Therefore, the potential deleterious effects of hypoxia on sleep quality, sleep duration, neurobehavioural activity, and quality of life suggest that appropriate earlier use of oxygen therapy in those who are hypoxic is indicated.

\section{HYPOXIA AND LUNG INFLAMMATION IN CF}

CF airway inflammation is typified by the presence of neutrophils, along with neutrophil enzyme products such as elastase which cause lung damage. ${ }^{43}$ Neutrophils are attracted to the airway by interleukin-8 (IL-8), ${ }^{43}$ a chemokine released by airway epithelial cells and macrophages as part of the innate immune response to infection. IL-8 levels, along

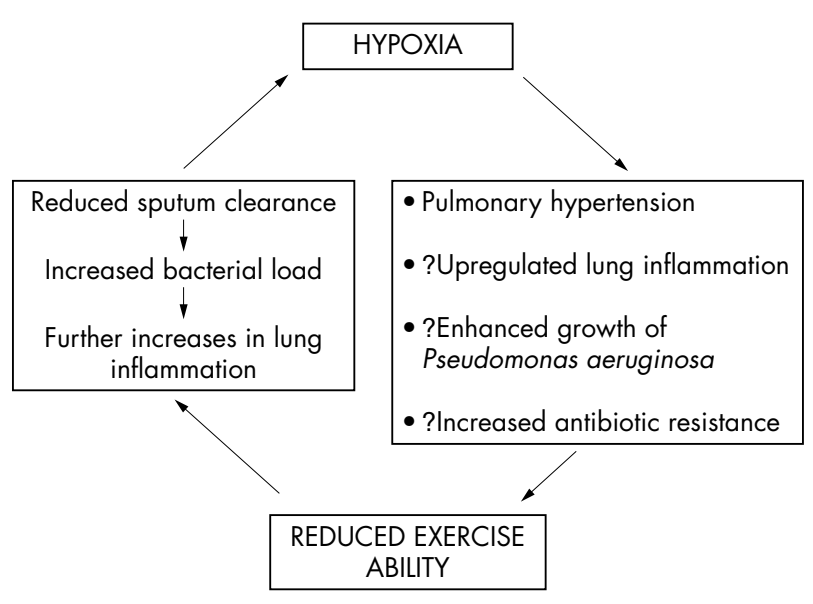

Figure 1 Hypoxia and its purported effects on exercise: "the vicious circle". with other pro-inflammatory cytokines such as tumour necrosis factor $\alpha(\mathrm{TNF} \alpha)$, IL-1 $\beta$, and IL- 6 are increased in the $\mathrm{CF}$ airway, ${ }^{43}$ and are regulated by transcription factors such as nuclear factor $\kappa \mathrm{B}(\mathrm{NF \kappa B}),{ }^{44}$ among others. The NFкB signalling pathway may be key to CF airway inflammation, ${ }^{44}$ and is a potentially attractive target for anti-inflammatory therapy in CF.

$\mathrm{NF \kappa B}$ is activated by factors including bacteria such as $\mathrm{PA}^{45}$ pro-inflammatory cytokines such as $\mathrm{TNF} \alpha,{ }^{46}$ and also possibly by hypoxia ${ }^{19}$ and mutant CFTR protein. ${ }^{47}$ Hence hypoxia driven NFKB activation may impact directly on lung inflammation in $\mathrm{CF}$ by increasing expression of cytokines which attract neutrophils and causing initiation then propagation of airway inflammation (fig 2). NFKB inhibitors used in the treatment of CF include corticosteroids, ${ }^{48}$ and non-steroidal anti-inflammatory drugs. ${ }^{49}$ Others such as cardiac glycosides are under investigation. ${ }^{50}$ The effects of oxygen therapy on CF lung inflammation have yet to be studied.

\section{HYPOXIA AND TISSUE EFFECTS OF INFLAMMATION}

The effects of hypoxia on up-regulating lung inflammation in CF may have far reaching effects on tissues including endothelium ${ }^{31}$ and skeletal muscle. ${ }^{29}$ Pro-inflammatory states promote body wasting, due to the catabolic effect of cytokines including IL-6, and TNF ${ }^{29}{ }^{29}$ Therefore, if hypoxia activates NFKB mediated inflammation, and up-regulates pro-inflammatory cytokine expression, this may detrimentally affect nutritional status. Resultant muscle wasting may decrease respiratory muscle strength, thus promoting nocturnal hypoventilation, and impeding exercise capacity. The associated worsening of hypoxia could cause a "downward pathophysiological spiral".

\section{SUPPORTING LABORATORY EVIDENCE OF A KEY ROLE FOR HYPOXIA IN MEDIATION OF CF LUNG INFLAMMATION}

The effects of hypoxia on lung inflammation remain speculative, but a role for oxygen as a therapy in downregulating lung inflammation in CF would be of great potential benefit.

In vitro evidence suggests that hypoxia up-regulates NFאB activation, ${ }^{19}$ which is potentially important in CF. While $\mathrm{NF \kappa B}$ activation due to hypoxia may be a direct effect, it is likely that other signalling pathways are involved to effect this action. Hypoxia enhances expression of $\mathrm{TNF} \alpha,{ }^{29}$ which in turn up-regulates NFкB. ${ }^{46}$ Hypoxia also changes PA growth patterns in the CF lung, ${ }^{20}$ increasing NFKB activation, ${ }^{51}$ and the effects of hypoxia on intracellular trafficking of CFTR protein may also be important. ${ }^{32}$ 


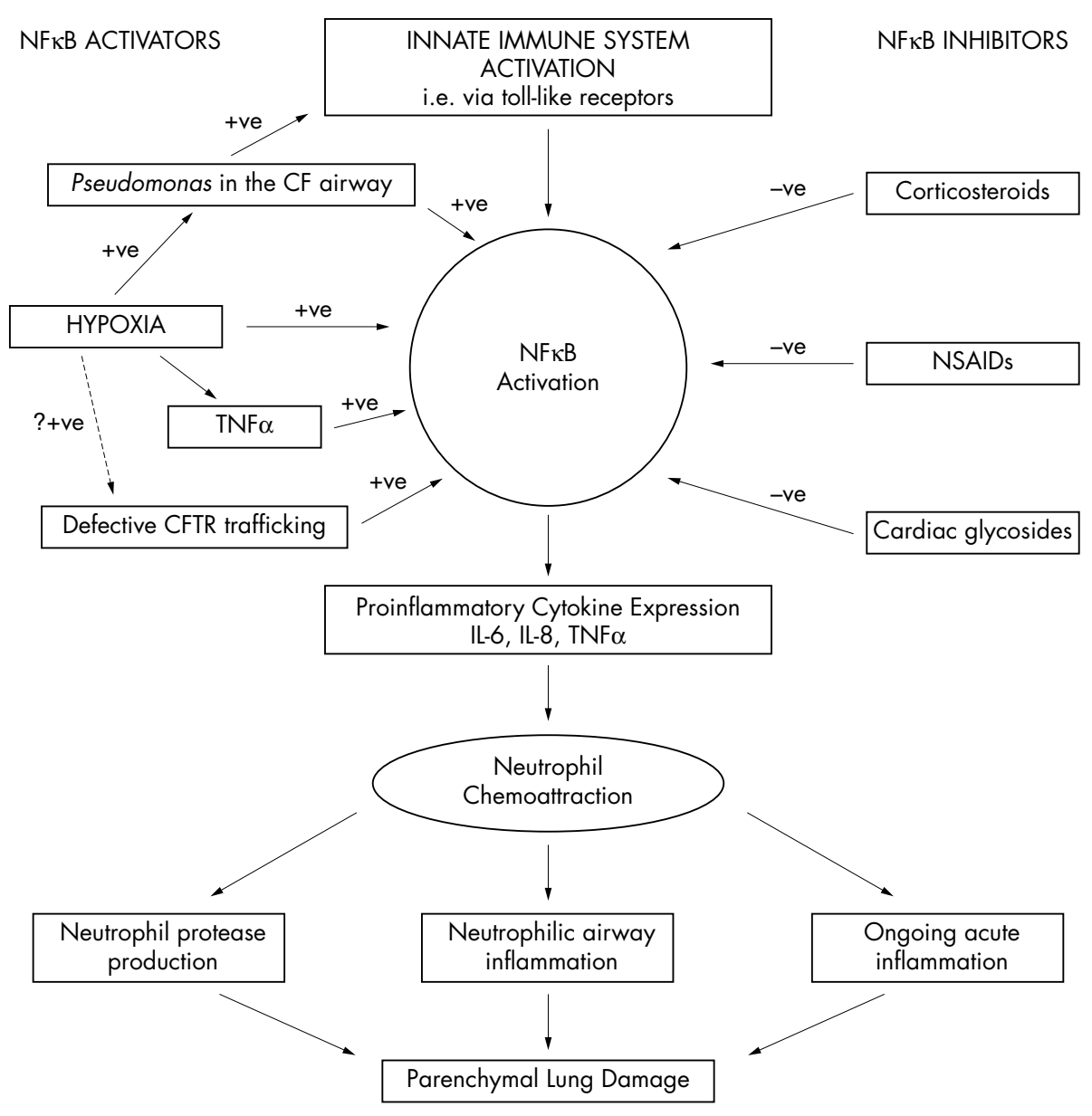

\section{Hypoxia and bacterial profile in the CF airway}

Pseudomonas aeruginosa (PA) produces bacterial lipopolysaccharide, which activates the innate immune system via Tolllike receptors (TLRs) on the airway epithelial cell surface. ${ }^{45}$ TLR signalling up-regulates $\mathrm{NF \kappa B},{ }^{45}$ and the consequential pro-inflammatory cytokine response ensues. By age 3 years, $73 \%$ of CF patients have had a PA lung infection, ${ }^{52}$ and the commonest cause of death in $\mathrm{CF}$ is unremitting lung disease associated with PA. ${ }^{53}$

PA changes phenotype under hypoxic conditions by forming biofilm-like macrocolonies. ${ }^{20}$ Hypoxia and the resultant biofilm state of PA leads to antibiotic resistance, ${ }^{28}$ and an increased ${ }^{51}$ and prolonged ${ }^{54}$ innate immune response. Hypoxia may therefore contribute to the persistence of PA infection in the CF lung and its associated chronic airways damage. The question of whether oxygen therapy might prevent a switch in PA phenotype remains unanswered, though the steep gradient that exists between airway lumen and the interior of $\mathrm{CF}$ airway mucus ${ }^{20}$ means that oxygen must penetrate the mucus to exert an effect.

\section{Hypoxia and CFTR protein}

Evidence exists that $\mathrm{CF}$ patients with the $\Delta \mathrm{F} 508$ mutation (85\% UK CF patients) have an ongoing process of NFKB driven inflammation, due to cell stress caused by overload of CFTR in the endoplasmic reticulum (ER) ${ }^{47}$ This implies that neutrophilic inflammation in the CF airway may be associated with CFTR dysfunction as well as infection. Thus, if CFTR trafficking to the cell surface could be improved, inflammation might be reduced. In vitro work has shown increased NFKB activation and IL-8 expression in $\Delta$ F508 CF cell lines compared with non-CF cells, ${ }^{55}$ while in vivo studies report increased IL-8 levels and neutrophil numbers in bronchoalveolar lavage (BAL) fluid of young children $^{5657}$ and infants ${ }^{58}$ with CF in the absence of evidence of infection. A single study suggests that cell surface CFTR protein expression in a renal cell line is impaired under hypoxic conditions, ${ }^{32}$ and reports that improved cellular oxygenation increases CFTR trafficking to the cell surface. In vivo work also suggests that hypoxia might inhibit CFTR function. In mountaineers with high altitude pulmonary oedema, CFTR mRNA levels fell by $60 \%$ at altitude, ${ }^{59}$ and it is possible that a trafficking deficit may account for such CFTR dysfunction under hypoxic conditions.

Disease severity in CF correlates with the amount of functional CFTR protein expressed at the apical cell surface of airway epithelial cells, ${ }^{60}$ and much research has focused on "molecular chaperoning" ${ }^{61}$ to guide $\Delta$ F508 CFTR protein from the ER to the cell surface. Various compounds from curcumin ${ }^{62}$ to sildenafil (Viagra) ${ }^{63}$ have been touted as successful, but as yet, the trafficking effects of oxygen in a $\Delta$ F508 CF cell line remain undocumented, but represent a potential novel therapy.

\section{UNANSWERED QUESTIONS ABOUT OXYGEN THERAPY IN CF \\ When to start and how much?}

In patients with evidence of chronic hypoxia, it appears that oxygen may be a therapy with exciting potential benefits in CF. Oxygen may improve quality of life, and beneficially modulate both heart and pulmonary circulatory responses, as well as exerting potential anti-inflammatory, antimicrobial, and anabolic effects. 
The question of when to start oxygen remains unanswered. Previous UK consensus advocated consideration of oxygen therapy when resting $\mathrm{SaO}_{2}$ is $<90 \%{ }^{64}$ However, although all patients with daytime $\mathrm{SaO}_{2}<90 \%$ would be expected to have night-time hypoxia, many with night-time hypoxia would be missed were this the sole rationale for prescribing. ${ }^{11}{ }^{14}$ The

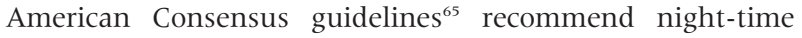
oxygen in adults if $\mathrm{SaO}_{2}$ is below $88-90 \%$ for $\geqslant 10 \%$ of sleep time, and oxygen during exercise if $\mathrm{SaO}_{2}$ falls below $88-90 \%$ during exercise. It is not clear how best to manage children who desaturate during exercise, or who dip by $4 \%$ but do not reach this threshold. In adult COPD models, LTOT is known to decrease mortality in patients with severe hypoxaemia, ${ }^{66} 67$ but in patients with night-time hypoxia only, no significant survival improvements were noted. ${ }^{68}$ Further work in CF is required to answer the questions of when to start oxygen, how much oxygen should be given, and for how long.

POTENTIAL HAZARDS OF OXYGEN THERAPY IN CF It is important to recognise the potentially detrimental effects of oxygen for a child with CF. Such potential detrimental effects fall largely into three groups. Firstly, children with CF already carry a heavy burden of care ${ }^{69}$ Oxygen may be poorly tolerated, it has household safety implications, and space may be taken up by oxygen concentrators in bedrooms that already contain medical equipment. The presence of oxygen in the family home may necessitate behavioural change from parents, including the (beneficial) cessation of smoking. Advice must also be given about the risk of naked flames. ${ }^{70}$ Meanwhile, oxygen therapy may be seen as palliative rather than active therapy, and the accompanying psychomorbidity must not be underestimated. This is highlighted by the only trial of long term oxygen therapy in $\mathrm{CF}^{7}{ }^{7}$ in which more than half of the 146 subjects approached refused to take part. Secondly, oxygen therapy may theoretically blunt respiratory drive. However, while short term studies have shown small rises in transcutaneous $\mathrm{pCO}_{2}$ with oxygen therapy during sleep, $^{71}{ }^{72}$ and exercise, ${ }^{38}$ these rises are of doubtful clinical significance. The only paper to study long term oxygen therapy did not find a rise in arterial $\mathrm{pCO}_{2}$ after one year. Finally, hyperoxia itself may cause free radical damage, and may up-regulate $\mathrm{NF \kappa B} .^{73}$

However, despite such caveats, the evidence reviewed suggests that earlier use of oxygen therapy in CF is worthy of exploration through the conduct of appropriately designed and powered randomised trials.

\section{SUMMARY}

Cystic fibrosis may lead to reduced oxygen content in arterial blood. Studies of the impact of this phenomenon on disease progression and outcome have been hampered by the lack of a consensus definition of hypoxia-in terms of both its timing (during sleep, rest, or exercise) and magnitude. Indeed, less than a quarter of UK CF centres utilise a clinical definition of hypoxia in routine care. ${ }^{10}$

Even if uniform diagnostic criteria were to be available, proof that oxygen therapy impacts on disease progression and outcome is not strong. However, our review of the basic science and rodent literature suggests that lower arterial oxygenation does have the capacity to impact in this way. Although human data are sparse, such data as do exist would also support this conjecture: CF patients with periods of hypoxia may have increased pulmonary artery pressures, increased lung inflammation, greater levels of Pseudomonas aeruginosa burden, reduced exercise ability and skeletal muscle strength, and perhaps most importantly of all, worse sleep quality and quality of life.

Perhaps due to the lack of adequate definitions and subsequent appropriately powered trials, there is similarly

\section{Key points}

- A consensus on definition of hypoxia in childhood CF is needed

- Daytime oximetry is a poor predictor of overnight oxygen saturations

- Overnight oximetry is needed to confidently detect nocturnal hypoxaemia in CF

- In those with exercise induced hypoxaemia, sleep and echocardiographic studies are recommended

- A fuller understanding of the effects of hypoxia in CF is needed

- A consensus on when to start oxygen therapy in children with CF is needed

- The question of whether oxygen ameliorates the adverse effects of CF hypoxia may need to be addressed by way of a randomised, controlled trial

no consensus as to when (and if) oxygen therapy should be initiated, nor for its mode or duration of delivery. The need for studies to document the prevalence and potential adverse effects of hypoxia in CF patients is thus apparent. For the time being, the need for overnight sleep studies to confidently detect nocturnal hypoxaemia in CF is reinforced by the poor sensitivity of daytime assessments, ${ }^{11}{ }^{14}$ and the presence of abnormal overnight oximetry in stable childhood $\mathrm{CF}^{2}$ It also seems sensible to seek evidence of exercise induced hypoxaemia. This occurs frequently in CF, and may indicate the need for a sleep study because of the association between sleep and exercise hypoxaemia. ${ }^{13}$ An echocardiogram should also be considered as pulmonary artery pressure may correlate with exercise associated desaturation. ${ }^{17}$

The potential role of oxygen therapy improving disease progress or outcome also warrants further study: a theoretical case that earlier institution of oxygen therapy in CF may improve clinical phenotype by slowing lung function decline and enhancing quality of life is made. This is not a call for oxygen therapy in all CF patients, rather a recognition that some hypoxic CF patients may be under-treated. A uniform approach to defining hypoxia in CF needs to be developed, along with guidelines for oxygen prescribing in CF. We recommend that any change in practice must be evidence based, and needs to be prefaced by appropriately powered randomised controlled trials.

\section{ACKNOWLEDGEMENTS}

Many thanks to Ms Ammani Prasad and Dr Kevin Southern for their help in the preparation of this manuscript.

\section{Authors' affiliations}

D S Urquhart, A Jaffé, Portex Anaesthesia, Intensive Therapy and Respiratory Medicine Unit, Institute of Child Health, and Great Ormond Street Hospital for Children NHS Trust, London, UK

H Montgomery, Centre for Aviation, Space and Extreme Environment Medicine, University College London, UK

Competing interests: none

\section{REFERENCES}

1 Bradley S, Solin P, Wilson J, et al. Hypoxemia and hypercapnia during exercise and sleep in patients with cystic fibrosis. Chest 1999;1 16:647-54.

2 Darracott C, McNamara PS, Pipon M, et al. Towards the development of cumulative overnight oximetry curves for children with cystic fibrosis. Journal of Cystic Fibrosis 2004;3(suppl 1):S53.

3 Narang I, Pike S, Rosenthal $M$, et al. Three-minute step test to assess exercise capacity in children with cystic fibrosis with mild lung disease. Pediatr Pulmonol 2003;35:108-13. 
4 Buchdahl RM, Babiker A, Bush A, et al. Predicting hypoxaemia during flights in children with cystic fibrosis. Thorax 2001;56:877-9.

5 Betancourt M, Slade G, Dinwiddie R. Oxygen saturations in cystic fibrosis. Arch Dis Child 1991;66:1075-6.

6 Balfour-Lynn IM, Primhak RA, Shaw BNJ. Home oxygen for children-who, how and when? Thorax 2005;60:76-81.

7 Zinman R, Corey M, Coates AL, et al. Nocturnal home oxygen in the treatment of hypoxemic cystic fibrosis patients. J Pediatr 1989;114:368-77.

8 Yildizdaș D, Yapicioğlu H, Yilmaz HL, et al. Correlation of simultaneously obtained capillary, venous, and arterial blood gases of patients in a paediatric intensive care unit. Arch Dis Child 2004;89:176-80.

9 Soubani AO. Noninvasive monitoring of oxygen and carbon dioxide Am J Emerg Med 2001;19:141-6.

10 Southern KW. Nocturnal hypoxia in CF. 2004 (personal communication).

11 Frangiolis DD, Wilcox PG. Predictability of oxygen desaturation during sleep in patients with cystic fibrosis. Chest 2001;119:434-41.

12 Tepper RS, Skatrud JB, Dempsey JA. Ventilation and oxygenation changes during sleep in cystic fibrosis. Chest 1983:84:388-93.

13 Coffey MJ, Fitzgerald MX, McNicholas WT. Comparison of oxygen desaturation during sleep and exercise in patients with cystic fibrosis. Chest 1991;100:659-62.

14 Milross MA, Piper AJ, Norman M, et al. Predicting sleep-disordered breathing in patients with cystic fibrosis. Chest 2001;120:1239-45.

15 Versteegh FG, Bogaard JM, Raatgever JW, et al. Relationship between airway obstruction, desaturation during exercise and nocturnal hypoxaemia in cystic fibrosis. Eur Respir $J$ 1990;3:68-73.

16 Urschitz MS, Wolff J, von Einem V, et al. Reference values for nocturnal home pulse oximetry during sleep in primary school children. Chest 2003; 123:96-101.

17 Fraser KL, Tullis DE, Sason Z, et al. Pulmonary hypertension and cardiac function in adult cystic fibrosis: role of hypoxaemia. Chest 1999;115:1321-8.

18 Milross MA, Piper AJ, Norman M, et al. Subjective sleep quality in cystic fibrosis. Sleep Med 2002;3:205-12.

19 Leeper-Woodford SK, Detmer K. Acute hypoxia increases alveolar macrophage tumor necrosis factor activity and alters NF- $\mathrm{kB}$ expression Am J Physiol Lung Cell Mol Physiol 1999;276:L909-16.

20 Worlitzsch D, Tarran R, Ulrich M, et al. Effect of reduced mucus oxygen concentration in airway Pseudomonas infections of cystic fibrosis patients. J Clin Invest 2002;109:317-25.

21 Nourry C, Fabre C, Bart F, et al. Evidence of exercise-induced arterial hypoxaemia in prepubescent trained children. Pediatr Res 2004;55:674-81

22 Cystic Fibrosis Trust, British Paediatric Association, British Thoracic Society. Clinical guidelines for cystic fibrosis care. London: Royal College of Physicians, 1996

23 Dobbin CJ, Bartlett D, Melehan K, et al. The effect of infective exacerbations on sleep and neurobehavioural function in cystic fibrosis. Am J Respir Crit Care Med 2005;172:99-104.

24 Oades PJ, Buchdahl RM, Bush A. Prediction of hypoxaemia at high altitude in children with cystic fibrosis. BMJ 1994;308:15-18.

25 Fischer R, Lang SM, Bruckner $\mathrm{K}$, et al. Lung function in adults with cystic fibrosis at altitude: impact on air travel. Eur Respir J 2005;25:718-24.

26 British Thoracic Society Standards of Care Committee. Managing passengers with respiratory disease planning air travel: British Thoracic Society recommendations. Thorax 2002;57:289-304.

27 British Thoracic Society. Managing passengers with respiratory disease planning air travel. 2004 British Thoracic Society recommendations. Summary of changes since 2002. http://www. brit-thoracic.org.uk/c2/uploads/ FlightSummary04.pdf.

28 Boriello G, Werner E, Roe F, et al. Oxygen limitation contributes to antibiotic tolerance of Pseudomonas aeruginosa in biofilms. Antimicrob Agents Chemother 2004;48:2659-64.

29 Gan WQ, Man SFP, Senthilselvan A, et al. Association between chronic obstructive pulmonary disease and systemic inflammation: a systematic review and meta-analysis. Thorax 2004;59:574-80

30 Cramton SE, Ulrich M, Gotz F, et al. Anaerobic conditions induce expression of polysaccharide intercellular adhesin in Staphylococcus aureus and Staphylococcus epidermidis. Infect Immun 2001;69:4079-85.

31 Ten VS, Pinsky DJ. Endothelial response to hypoxia: physiologic adaptation and pathologic dysfunction. Curr Opin Crit Care 2002;8:242-50.

32 Bebok Z, Tousson A, Schwiebert L, et al. Improved oxygenation promotes CFTR maturation and trafficking in MDCK cell monolayers. Am J Physiol Cell Physiol 2001;280:C135-45

33 Wiglesworth FW. Fibrocystic disease of the pancreas. Am J Med Sci 1946;212:351-65.

34 Bright-Thomas RJ, Webb AK. The heart in cystic fibrosis. J R Soc Med 2002;95(suppl 41):2-10.

35 Ryland D, Reid L. The pulmonary circulation in cystic fibrosis. Thorax 1975;30:285-92.

$36 \mathrm{Klijn} \mathrm{PH}$, Oudshoorn A, van der Ent CK, et al. Effects of anaerobic training in children with cystic fibrosis: a randomized controlled study. Chest 2004; 125:1299-305.

37 Deboeck G, Niset G, Lamotte $M$, et al. Exercise testing in pulmonary hypertension and in chronic heart failure. Eur Respir $J$ 2004;23:747-51.

38 Marcus CL, Bader D, Stabile MW, et al. Supplemental oxygen and exercise performance in patients with cystic fibrosis with severe pulmonary disease. Chest 1992;101:52-7.
39 McKone EF, Barry SC, Fitzgerald MX, et al. The role of supplemental oxygen during submaximal exercise in patients with cystic fibrosis. Eur Respir J 2002;20:134-42.

40 Hoo GW. Nonpharmacologic adjuncts to training during pulmonary rehabilitation: the role of supplemental oxygen and non-invasive ventilation $J$ Rehabil Res Dev 2003;40(suppl 2):81-98.

41 Kusenbach G, Weiching R, Barker $M$, et al. Effects of hyperoxia on oxygen uptake kinetics in cystic fibrosis patients as determined by pseudo-random binary sequence kinetics. Eur J Appl Physiol Occup Physiol 1999;79:192-6.

42 Emtner M, Porszasz J, Burns $M$, et al. Benefits of supplemental oxygen in exercise training in non-hypoxemic COPD patients. Am J Respir Crit Care Med 2003;68:1034-42.

43 Chmiel JF, Davis PB. Why do the lungs of cystic fibrosis patients become infected and why can't they clear the infection? Respir Res 2003;4:8-19.

44 Hershenson MB. Signaling pathways initiating CF airway inflammation. Pediatr Pulmonol 2004;38(suppl 27):167-8.

45 Haijar AM, Ernst RK, Tsai JH, et al. Human Toll-like receptor 4 recognises host-specific LPS modifications. Nature Immunology 2002;3:354-9.

46 Brightbill ID, Modlin RL. Toll-like receptors: molecular mechanisms of the mammalian immune response. Immunology 2000;101:1-10.

47 Baeverle PA, Baltimore D. NFKB: ten years after. Cell 1995;87:13-20.

48 Auerbach HS, Williams M, Kirkpatrick JA, et al. Alternate-day prednisolone improves pulmonary function in cystic fibrosis. Lancet 1985;2:686-8.

49 Konstan MW, Byard PJ, Hoppel CL, et al. Effect of high-dose ibuprofen in patients with cystic fibrosis. N Engl J Med 1995;332:848-54.

50 Yang Q, Huang W, Jozwik C, et al. Inhibition of NFKB signaling pathway by digitoxin and related cardiac glycoside drugs. Pediatr Pulmonol 2004;27(suppl):46.

51 Muhlebach MS, Stewart PW, Leigh MW, et al. Quantitation of inflammatory responses to bacteria in young cystic fibrosis and control patients. Am J Respir Crit Care Med 1999;160:186-91.

52 Burns JL, Gibson RL, McNamara S, et al. Longitudinal assessment of Pseudomonas aeruginosa in young children with cystic fibrosis. J Infect Dis 2001; 183:444-52.

53 Davis PB, Drumm M, Konstan MW. Cystic fibrosis. Am J Respir Crit Care Med 1996; 154:1229-56

54 Kube D, Sontich U, Fletcher D, et al. Proinflammatory cytokine responses to $\mathrm{P}$. aeruginosa infection in human airway epithelial cell lines. Am J Physiol Lung Cell Mol Physiol 2001;280:L493-502

55 Weber AJ, Soong G, Bryan R, et al. Activation of NFkB in airway epithelial cells is dependent on CFTR trafficking and $\mathrm{Cl}^{-}$channel function. Am J Physiol Lung Cell Mol Physiol 2001;281:L71-8.

56 Balough $K$, McCubbin $M$, Weinberger $M$, et al. The relationship between infection and inflammation in the early stages of lung disease from cystic fibrosis. Pediatr Pulmonol 1995;20:63-70.

57 Noah TL, Black HR, Cheng PW, et al. Nasal and bronchoalveolar lavage fluid cytokines in early cystic fibrosis. J Infect Dis 1997;175:638-47.

58 Khan TZ, Wagener JS, Bost T, et al. Early pulmonary inflammation in infants with cystic fibrosis. Am J Respir Crit Care Med 1995;151:939-41.

59 Mairbaurl H, Schwobel F, Hoschele S, et al. Altered ion transporter expression in bronchial epithelium in mountaineers with high-altitude pulmonary oedema. J Appl Physiol 2003;95:1843-50.

60 Schwiebert LM. How much CFTR is needed to attenuate lung inflammation? Pediatr Pulmonol 2004;38(suppl 27):96-7.

61 Morello J-P, Petaja-Repo UE, Bichet DG, et al. Pharmacological chaperones: a new twist on receptor folding. Trends Pharmacol Sci 2000;21:466-9.

62 Egan ME, Pearson M, Weiner SA, et al. Curcumin, a major constituent of turmeric, corrects cystic fibrosis defects. Science 2004;304:600-2.

63 Dormer RL, Harris CM, Clark Z, et al. Sildenafil (Viagra) corrects $\triangle$ F508-CFTR location in nasal epithelial cells from patients with cystic fibrosis. Thorax 2005;60:55-9

64 Dinwiddie R, Madge S, Prasad SA, et al. Oxygen therapy for cystic fibrosis. $J$ R Soc Med 1999;92(suppl 37):19-22.

65 Yankaskas JR, Marshall BC, Sufian B, et al. Cystic fibrosis adult care: consensus conference report. Chest 2004;125(suppl 1):1S-39S

66 Medical Research Council Working Party. Long-term domiciliary oxygen therapy in chronic hypoxic cor pulmonale complicating chronic bronchitis and emphysema. Lancet 1981;1:681-6.

67 Timms RM, Khaja FU, Williams GW, et al. Hemodynamic response to oxygen therapy in chronic obstructive pulmonary disease. Ann Intern Med 1985;102:29-36.

68 Crockett AJ, Cranston JM, Moss JR, et al. Domiciliary oxygen for chronic obstructive pulmonary disease. Cochrane Database Syst Rev 2000:4:CD001744.

69 Hunter V. The daily grind and how to stay sane as a mother of two children with cystic fibrosis. J R Soc Med 2003;96(suppl 43):51-6.

70 Laubscher B. Home oxygen therapy: beware of birthday cakes. Arch Dis Child 2003;88:1125.

71 Spier S, Rivlin J, Hughes D, et al. The effect of oxygen on sleep, blood gases and ventilation in cystic fibrosis. Am Rev Respir Dis 1984;129:712-18.

72 Gozal D. Nocturnal ventilatory support in patients with cystic fibrosis: comparison with supplemental oxygen. Eur Respir J 1997;10:1999-2003.

73 Horowitz S. Pathways to cell death in hyperoxia. Chest 1999;116:64S-67S. 